\title{
Calcium-dependent serine-threonine phosphatase, calcineurin inactivation mediated by baicalein attenuates prion protein-mediated neuronal cell damage
}

Jeong-Min Hong

Chonbuk National University - Specialized Campus

Ji-Hong Moon

Chonbuk National University - Specialized Campus

Sang-Youel Park ( $\nabla$ sypark@chonbuk.ac.kr)

Chonbuk National University - Specialized Campus https://orcid.org/0000-0003-0575-6045

Research article

Keywords: Prion, Calcineurin, Baicalein, Autophagy, Neuroinflammation

Posted Date: October 19th, 2020

DOl: https://doi.org/10.21203/rs.3.rs-18414/v3

License: (c) (i) This work is licensed under a Creative Commons Attribution 4.0 International License.

Read Full License 


\section{Abstract}

Background: Prion diseases are a group of unvaryingly fatal neurodegenerative disorders characterized by neuronal cell death. Calcineurin and autophagy mediate prion-induced neurodegeneration, suggesting that inhibition of calcineurin and autophagy could be a target for therapy. Baicalein has been reported to exert neuroprotective effects against calcium-dependent neuronal cell death.

Results: In the present study, we investigated whether baicalein attenuates prion peptide-mediated neurotoxicity and reduces calcineurin. We found that baicalein treatment inhibits prion protein-induced apoptosis. Baicalein inhibited calcium up-regulation and protected the cells against prion peptide-induced neuron cell death by calcineurin inactivation. Furthermore, baicalein increased p62 protein levels and decrease LC3-II protein levels indicating autophagic flux inhibition and baicalein inhibited prion proteininduced neurotoxicity through autophagy flux inhibition.

Conclusions: Taken together, this study demonstrated that baicalein attenuated prion peptide-induced neurotoxicity via calcineurin inactivation and autophagic flux reduction, and also suggest that baicalein may be an effective therapeutic drug against neurodegenerative diseases, including prion diseases.

\section{Background}

Prion diseases, known as transmissible spongiform encephalopathies (TSEs), are fatal neurodegenerative disorders. They include kuru and sporadic Creutzfeldt-Jakob disease in humans, bovine spongiform encephalopathies in cattle, and scrapie in sheep and goats [1,2]. Prion diseases are characterized by misfolding of normal cellular prion protein $\left(\mathrm{PrP}^{\mathrm{C}}\right)$ into scrapie prion protein $(\mathrm{PrPSc})$, which is an abnormal protease-resistant misfolded isoform [3, 4]. $\mathrm{PrP}^{\mathrm{C}}$ is soluble, with a predominant alpha-helical conformation, but a disease-causing, infectious form ( $\mathrm{PrPSc}$ ) is insoluble, $\beta$-sheet-rich, and protease-resistant [5]. Because of $\beta$-sheet-rich conformation, $\mathrm{PrPSc}^{\mathrm{Sc}}$ is highly pathogenic and neurotoxic when compared with the largely a-sheet-rich structure of $\operatorname{PrP}^{\mathrm{C}}[6,7]$. $\operatorname{PrP}^{\mathrm{Sc}}$ is a misfolded protein aggregate accumulating within endosomes or on the neuronal cell surface. It leads to cytotoxicity and cell death [8-10].

Baicalein is a major flavonoid originally extracted from the roots of a traditional Chinese medicinal herb Scutellaria baicalensis Georgi. Baicalein exhibits several pharmacological activities, such as antiinflammatory and anti-oxidative properties [11,12], and exerts protective effects against ischemic brain injury [13], Parkinson's disease [14, 15], A $\beta$-induced toxicity [16], and experimental traumatic brain injury [17]. Baicalein prevents elevation of intracellular calcium in Parkinson's disease [18] and attenuates the expression of calcineurin protein in cardiac remodeling [19].

Calcineurin or protein phosphatase 2B (PP2B) is highly abundant in the brain and regulates synaptic plasticity and neuronal death [20]. Calcineurin immunoreactivity occurs exclusively in the neurons throughout brain [21, 22]. Overactivation of calcineurin by amyloid-beta and prion proteins induces 
neurotoxicity [3, 23]. Tacrolimus or FK506 is a well-known immunosuppressive drug, which binds to the FK506-binding protein (FKBP). The FK506-FKBP12 complex binds to calcineurin and inhibits its activity [24].

Autophagy is a highly conservative cellular process in which cells degrade and recycle bulk cytosolic proteins and damaged organelles via lysosomal degradation $[25,26]$. Importantly, autophagy plays an important role in the survival of neural cells $[27,28]$. Autophagy plays a key role in inflammatory diseases, and protein misfolding diseases [29]. However, the role of autophagy in baicalein-mediated neuroprotective effects is not fully understood.

Our previous study showed that baicalein inhibits prion peptide-induced neuronal apoptosis by inhibiting JNK activation. However, the effect of baicalein on prion protein-induced neuronal cell damage via calcineurin and autophagy has yet to be reported. In this study, we observed the neuroprotective effects of baicalein against PrP (106-126)-mediated apoptosis, calcineurin and autophagy activation.

\section{Results}

\section{Baicalein inhibits prion peptide-induced neuronal apoptosis.}

We investigated whether baicalein affected prion peptide-induced neurotoxicity. The results showed that PrP (106-126) induced neuronal cell death, and baicalein reduced prion protein-mediated neurotoxicity (Figures $1 A$ and $B$ ). Using TUNEL assay, we demonstrated that baicalein attenuated DNA strand breakage caused by prion peptide (Figure 1C). These results suggest that baicalein attenuates PrP (106-126)induced neuronal apoptosis.

\section{Baicalein inhibits PrP (106-126)-induced apoptosis by calcineurin inactivation}

To determine the effect of baicalein on prion peptide expression in neuronal cells, we investigated the role of prion peptide in altering $\mathrm{Ca}^{2+}$ levels in neuronal cells. $\mathrm{Ca}^{2+}$ content was directly evaluated by prion peptide, and baicalein reduced PrP-induced $\mathrm{Ca}^{2+}$ (Figures $2 \mathrm{~A}$ and $\mathrm{B}$ ). Fluorescence imaging also indicated that baicalein inhibited calcium increase (Figure $2 \mathrm{C}$ ). The activity of calcineurin was evaluated by measuring the formation of free phosphate (), using a specific kit assay. The results showed that prion protein elevated calcineurin activity and baicalein reduced prion peptide-induced calcineurin activity (Figure 2D). Next, to investigate whether the inhibition of calcineurin exerts neuroprotective effects against PrP (106-126)-induced neurotoxicity, we analyzed the levels of calcineurin and cell viability using a calcineurin inhibitor (FK506). We also found that baicalein and calcineurin inhibitor blocked the PrP (106-126)-induced neuronal apoptosis (Figures 3A and B). TUNEL assay demonstrated that baicalein and calcineurin inhibitor reduced apoptosis in PrP (106-126)-treated cells resulting in DNA strand breakage (Figure $3 \mathrm{C}$ ). The results showed that baicalein and calcineurin inhibitor reduced prion protein-induced calcineurin activity (Figure 3D).

\section{Baicalein treatment inhibits PrP (106-126)-induced apoptosis via autophagy}


We investigated whether baicalein affects prion peptide-induced autophagy. We found that baicalein increased SQSTM1/p62 and decreased LC3-II (Figure 4A). Orange fluorescence was recovered by treatment with calcineurin inhibitor (Figure 4B). Prion peptide-induced autophagic flux was abolished by baicalein and confirmed by the induction of SQSTM1/p62 protein and the reduction of LC3-II protein (Figure 4C). We also conducted TEM to establish the effect of lysosomal inhibition of autophagy by baicalein. As shown in Figure 4D, multiple vesicles including double-membraned autophagosomes (arrows) were reduced by treatment of baicalein, which indicated inhibition of autophagic flux and lysosomal degradation (Figure 4D). Next, to investigate whether the inhibition of autophagy exerted neuroprotective effects against PrP (106-126)-induced neurotoxicity, we analyzed the levels of autophagy and cell viability using an autophagy inhibitor (chloroquine). We also found that baicalein and autophagy inhibitor blocked PrP (106-126)-induced neuronal apoptosis (Figures 5A and B). TUNEL assay demonstrated that exposure to baicalein and autophagy inhibitor reduced DNA strand breakage caused by prion protein (Figure $5 \mathrm{C}$ ). Prion peptide-induced autophagic flux was abolished by baicalein and was confirmed by the upregulation of SQSTM1/p62 protein and the downregulation of LC3-II, and inhibition of prion peptide-induced autophagy was confirmed by the upregulation of SQSTM1/p62 protein and LC3-II (Figure 5D).

\section{Discussion}

The study was to investigate the role of baicalein in calcineurin inactivation and autophagy, and the regulation of PrP (106-126)-induced apoptosis by baicalein in neuronal cells. The results suggest that the decrease in calcineurin and autophagy by baicalein and the consequent reduction in prion proteininduced neurotoxicity may be the key mechanisms underlying the neuroprotective effects of baicalein.

It has been reported that baicalein inhibits intracellular $\mathrm{Ca}^{2+}$ concentrations by reducing phospholipase $\mathrm{C}$ activity in $\mathrm{C} 6$ rat glioma cells [30]. Wang et al suggested that the protective effect of baicalein is mediated via calcineurin pathway in angiotensin II-treated mice. Baicalein inhibits cardiac remodeling by attenuating calcineurin signaling pathways in mice [19]. Consistent with these findings, our results also demonstrated that baicalein attenuates calcineurin activity. Together, these findings suggest that baicalein effectively inhibits prion protein-induced calcium and calcineurin activity.

Because baicalein has neuroprotective and antioxidant properties, It has been reported to exert a neuroprotective effect against $ß$-amyloid peptide [31, 32], 6-OHDA-induced PD [15, 18] and human prion protein fragment 106-126 (PrP) [33]. A medicinal herb Scutellaria lateriflora is known to inhibit PrP replication in vitro and delay the onset of prion disease in Mice [34]. The neuroprotection of baicalein has been linked to its anti-apoptotic, anti-inflammatory and pro-differentiation mechanisms. This study explored the neuroprotective role of baicalein against prion protein-induced neurotoxicity.

Baicalein significantly increased the level of autophagy in cancer [35] and liver disease [36]. However, other studies report that baicalein attenuated autophagy [37]. In the present study, we showed that baicalein inhibited autophagy in neuronal cells. Autophagic defects are well documented in 
neurodegenerative diseases [38,39], and include accumulation of autophagosomes and undegraded autophagic vacuoles in neuronal cells [39-41].

Although prion peptide 106-126 was used more than 20 years as a model of prion disorders, the relevance of pathogenic mechanism is still controversial. The prion peptide PrP106-126 has been widely used as a suitable model peptide because this fragment is soluble in water and exhibits several physicochemical and biological properties similar to those of $\mathrm{PrPS}^{\mathrm{Sc}}$, such as aggregation in solution, antiproteinase $\mathrm{K}$ digestion, and neurotoxicity $[42,43]$. However, an important argument about PrP peptide 106-126 is the facts that it is not actually a fragment found in the brains of humans or animals with prion diseases[44]. Even we investigated baicalein effect in this study, we will further study the issue using longer fragments or full-length PrP mutant models to examine therapeutic potential of baicalein in prion disease.

\section{Conclusions}

In the future, we will further study the neuroprotective effects of baicalein, autophagy and the calcineurin pathway in mouse models to examine baicalein's potential therapeutic role in prion disease

\section{Methods}

\section{Cell culture}

The human neuroblastoma cell line SK-N-SH was obtained from the American Type Culture Collection (ATCC, Rockville, MD, USA) and cultured in Minimum Essential Medium (MEM, Hyclone Laboratories, Logan, UT, USA) with 10\% fetal bovine serum (Invitrogen-GIBCO, Grand Island, NY, USA) and $0.1 \mathrm{mg} / \mathrm{mL}$ gentamycin in a humidified environment at $37^{\circ} \mathrm{C}$ with $5 \% \mathrm{CO} 2$.

\section{PrP (106-126) treatment}

PrP (106-126) was synthesized as previously described [45]. Synthetic PrP (106-126) peptides (sequence, Lys-Thr-Asn-Met-Lys-His-Met-Ala-Gly-Ala-Ala-Ala-Ala-Gly-Ala-Val-Val-Gly-Gly-Leu-Gly) were synthesized by Peptron (Seoul, Korea). The peptides were dissolved in sterile dimethyl sulfoxide at a stock concentration of $10 \mathrm{mM}$ and stored at $-20^{\circ} \mathrm{C}$.

\section{Annexin V/Propidium iodide (PI) test}

Apoptosis in detached 5,000 cells was assessed using an annexin V Assay kit (Santa Cruz Biotechnology, Santa Cruz, CA, USA) according to the manufacturer's protocol. Cells were incubated in the dark for 30 min. Annexin $V$ levels were determined by measuring fluorescence at $488 \mathrm{~nm}$ excitation and 525/30 emission using a Guava EasyCyte HT System (Millipore, Bedford, MA, USA).

\section{Measurement of $\left[\mathrm{Ca}^{2+}\right] i$}


Measurement of $\mathrm{Ca}^{2+}$ contents was measured as previously reported [46]. Briefly, cells were plated on collagen-coated confocal dish. Incubation with $5 \mu$ M Fluo-4 AM (Invitrogen) in media containing 1\% FBS was carried out for $40 \mathrm{~min}$ at $37^{\circ} \mathrm{C}$ and then washed three times with Hank's Balanced Salt Solution (HBSS). Changes of $\left[\mathrm{Ca}^{2+}\right]$ i were determined at $488 \mathrm{~nm}$ excitation/530 nm emission using an air-cooled argon laser system. The fluorescence emitted at $530 \mathrm{~nm}$ was collected using a photomultiplier. The image was scanned using a confocal microscope (Zeiss). For the calculation of $\left[\mathrm{Ca}^{2+}\right]$, the method of Tsien et al. [47] was used.

\section{Calcineurin activity assay}

The calcineurin cellular activity assay kit (\#BML-AK816-0001; Enzo Life Sciences, Inc., Farmingdale, NY, USA) was used to determine the phosphatase activity of calcineurin in neuronal cells, using the manufacturer's instructions. Calcineurin activity was measured as previously reported [48]. In brief, the cells were lysed on ice in a lysis buffer containing protease inhibitors. Phosphatase activity was quantified by detection of free phosphate released from the reaction based on the absorbance of malachite green (OD $620 \mathrm{~nm}$ ).

\section{Terminal deoxynucleotidyl transferase dUTP nick end labeling (TUNEL) assay.}

TUNEL assay was performed to measure the degree of cellular apoptosis using a TUNEL-based assay kit (BioVision, Mountain View, CA, USA). TUNEL analysis was performed according to the manufacturer's instructions. The cells were counterstained with propidium iodide $(\mathrm{PI})$ for nuclei.

\section{Western blot analysis}

SK-N-SH cells were lysed in a lysis buffer [25 mM HEPES at pH 7.4, $100 \mathrm{mM} \mathrm{NaCl}, 1 \mathrm{mM}$ EDTA, $5 \mathrm{mM}$ $\mathrm{MgCl}_{2}, 0.1 \mathrm{mM} \mathrm{DTT}$ (dithiothreitol), and a protease inhibitor mixture]. Equal amounts of lysate whole cell proteins were electrophoretically resolved on a $10 \%-15 \%$ sodium dodecyl sulfate polyacrylamide gel and transferred to a nitrocellulose membrane. Immunoreactivity was detected via sequential incubation with primary antibodies, horseradish peroxidase-conjugated secondary antibodies, and enhanced chemiluminescence reagents (West Save Gold detection kit; AbFrontier, Seoul, Rep. of Korea). The primary antibodies used for immunoblotting were anti-P62 (\#5114; Cell Signaling Technology), LC3 (Novus Biologicals, Littleton, CO, USA), and anti- $\beta$-actin (A5441; Sigma-Aldrich, St. Louis, MO, USA). Images were analyzed using a Fusion FX7 imaging system (Vilber Lourmat, Torcy Z.I. Sud, France). Densitometry was used to analyze the signal bands with the Bio-1D software package (Vilber Lourmat, Marne La Vallee, France).

\section{Fluorescence microscopy}

After treatment, coverslips were mounted with $70 \%$ ethanol in DW for 10 min at RT. Cells were stained with $\mathrm{AO}(0.1 \mu \mathrm{g} / \mathrm{mL})$ for $20 \mathrm{~min}$ in a cell culture incubator. Excitation wavelengths were $543 \mathrm{~nm}$ and 633 $\mathrm{nm}$. Bandpass filters were set at 560-615 nm (Cy3, AlexaFluor568) and 650-750 nm (AlexaFluor647). 


\section{Transmission electron microscopy (TEM)}

TEM samples were analyzed by transmission electron microscope (JEM-2010, JEOL) installed in the Center for University-Wide Research Facilities (CURF) at Jeonbuk National University [49]. Briefly, TEM samples were analyzed by transmission electron microscope (JEM-2010, JEOL) installed in the Center for University-Wide Research Facilities (CURF) at Jeonbuk National University. After fixation of SK-N-SH cell samples in $2.5 \%$ glutaraldehyde (TED PELLA, USA) in PBS ( $\mathrm{pH}, 7.2)$, specimens were post fixed in $1 \%$ osmium tetroxide (Heraeus, South Africa), dehydrated in graded ethanol and propylene oxide (Acros Organics, USA), and then embedded in Epoxy resin (Embed812. NMA; Nadic methyl anhydride. DDSA; Dodenyl Succinic Anhidride. DMP-30., USA) as used previously. Serial ultrathin sections were cut on an LKB-III ultratome (LEICA, Germany). Ultrathin sections were stained with uranyl acetate (TED PELLA, USA) and lead citrate (TED PELLA, USA) and examined with the aid of a Hitachi H7600 electron microscope (Hitachi, Japan) at an accelerating voltage of $100 \mathrm{kV}$.

\section{Statistical analysis}

All data were expressed as mean \pm standard error, and compared using the one-way ANOVA followed by the Tukey test. All statistical analysis was performed using GraphPad Prism software. Results were considered significant at ${ }^{*} p<0.05,{ }^{\star \star} p<0.01$ or ${ }^{\star \star \star} p<0.001$, as appropriate.

\section{Declarations}

\section{Ethics approval and consent to participate}

Not applicable

\section{Consent for publication}

Not applicable

\section{Availability of data and materials}

The datasets used and/or analyzed during the current study are available from the corresponding author on reasonable request.

\section{Competing interests}

The authors declare that they have no competing interests

\section{Funding}

This study was supported by National Research Foundation of the Korea Grant (NRF) which was funded by Ministry of Education (2019R1A6A1A03033084). NRF did not play a role in the study design or analyses. 


\section{Author contributions}

$\mathrm{JH}$ and $\mathrm{JM}$ analyzed and interpreted all the data. $\mathrm{JH}$ performed the experiments and was a major contributor in writing the manuscript. SP contributed to study design and the writing of the manuscript. All authors read and approved the final manuscript.

\section{Acknowledgments}

Not applicable.

\section{Abbreviations}

BAI: baicalein; CNS: central nervous system; PrPc: cellular prion protein; PrPsc: scrapie-associated prion protein; LC3-I/II: microtubule-associated protein 1A/1B-light chain 3-I/Il; CQ: chloroquine

\section{References}

1. Nakagaki T, Satoh K, Ishibashi D, Fuse T, Sano K, Kamatari YO, Kuwata K, Shigematsu K, Iwamaru Y, Takenouchi T et al: FK506 reduces abnormal prion protein through the activation of autolysosomal degradation and prolongs survival in prion-infected mice. Autophagy 2013, 9(9):1386-1394.

2. Puig B, Altmeppen HC, Ulbrich S, Linsenmeier L, Krasemann S, Chakroun K, Acevedo-Morantes CY, Wille $\mathrm{H}$, Tatzelt J, Glatzel M: Secretory pathway retention of mutant prion protein induces p38-MAPK activation and lethal disease in mice. Sci Rep 2016, 6:24970.

3. Mukherjee A, Morales-Scheihing D, Gonzalez-Romero D, Green K, Taglialatela G, Soto C: Calcineurin inhibition at the clinical phase of prion disease reduces neurodegeneration, improves behavioral alterations and increases animal survival. PLoS Pathog 2010, 6(10):e1001138.

4. Mukherjee $\mathrm{A}$, Soto $\mathrm{C}$ : Role of calcineurin in neurodegeneration produced by misfolded proteins and endoplasmic reticulum stress. Curr Opin Cell Biol 2011, 23(2):223-230.

5. Caughey B, Baron GS, Chesebro B, Jeffrey M: Getting a grip on prions: oligomers, amyloids, and pathological membrane interactions. Annu Rev Biochem 2009, 78:177-204.

6. Song Z, Zhu T, Zhou X, Barrow P, Yang W, Cui Y, Yang L, Zhao D: REST alleviates neurotoxic prion peptide-induced synaptic abnormalities, neurofibrillary degeneration and neuronal death partially via LRP6-mediated Wnt-beta-catenin signaling. Oncotarget 2016, 7(11):12035-12052.

7. Prusiner SB: Prions. Proc Natl Acad Sci U S A 1998, 95(23):13363-13383.

8. Olzscha H, Schermann SM, Woerner AC, Pinkert S, Hecht MH, Tartaglia GG, Vendruscolo M, HayerHartl M, Hartl FU, Vabulas RM: Amyloid-like aggregates sequester numerous metastable proteins with essential cellular functions. Cel/ 2011, 144(1):67-78.

9. Stefani M, Dobson CM: Protein aggregation and aggregate toxicity: new insights into protein folding, misfolding diseases and biological evolution. J Mol Med (Berl) 2003, 81(11):678-699. 
10. Winklhofer KF, Tatzelt J, Haass C: The two faces of protein misfolding: gain- and loss-of-function in neurodegenerative diseases. Embo j 2008, 27(2):336-349.

11. Chen HM, Hsu JH, Liou SF, Chen TJ, Chen LY, Chiu CC, Yeh JL: Baicalein, an active component of Scutellaria baicalensis Georgi, prevents lysophosphatidylcholine-induced cardiac injury by reducing reactive oxygen species production, calcium overload and apoptosis via MAPK pathways. BMC Complement Altern Med 2014, 14:233.

12. Li FQ, Wang T, Pei Z, Liu B, Hong JS: Inhibition of microglial activation by the herbal flavonoid baicalein attenuates inflammation-mediated degeneration of dopaminergic neurons. J Neural Transm (Vienna) 2005, 112(3):331-347.

13. Liu C, Wu J, Xu K, Cai F, Gu J, Ma L, Chen J: Neuroprotection by baicalein in ischemic brain injury involves PTEN/AKT pathway. J Neurochem 2010, 112(6):1500-1512.

14. Chen CC, Chow MP, Huang WC, Lin YC, Chang YJ: Flavonoids inhibit tumor necrosis factor-alphainduced up-regulation of intercellular adhesion molecule-1 (ICAM-1) in respiratory epithelial cells through activator protein-1 and nuclear factor-kappaB: structure-activity relationships. $\mathrm{Mol}$ Pharmacol 2004, 66(3):683-693.

15. Mu X, He G, Cheng Y, Li X, Xu B, Du G: Baicalein exerts neuroprotective effects in 6-hydroxydopamineinduced experimental parkinsonism in vivo and in vitro. Pharmacol Biochem Behav 2009, 92(4):642648.

16. Lebeau A, Esclaire F, Rostene W, Pelaprat D: Baicalein protects cortical neurons from beta-amyloid (25-35) induced toxicity. Neuroreport 2001, 12(10):2199-2202.

17. Chen SF, Hsu CW, Huang WH, Wang JY: Post-injury baicalein improves histological and functional outcomes and reduces inflammatory cytokines after experimental traumatic brain injury. $\mathrm{Br} \mathrm{J}$ Pharmacol 2008, 155(8):1279-1296.

18. Wang SF, Liu LF, Wu MY, Cai CZ, Su H, Tan J, Lu JH, Li M: Baicalein prevents 6-OHDA/ascorbic acidinduced calcium-dependent dopaminergic neuronal cell death. Sci Rep 2017, 7(1):8398.

19. Wang AW, Song L, Miao J, Wang HX, Tian C, Jiang X, Han QY, Yu L, Liu Y, Du J et al: Baicalein attenuates angiotensin II-induced cardiac remodeling via inhibition of AKT/mTOR, ERK1/2, NFkappaB, and calcineurin signaling pathways in mice. Am J Hypertens 2015, 28(4):518-526.

20. Mansuy IM: Calcineurin in memory and bidirectional plasticity. Biochem Biophys Res Commun 2003, 311(4):1195-1208.

21. Goto S, Matsukado Y, Mihara Y, Inoue N, Miyamoto E: The distribution of calcineurin in rat brain by light and electron microscopic immunohistochemistry and enzyme-immunoassay. Brain Res 1986, 397(1):161-172.

22. Goto S, Matsukado Y, Mihara Y, Inoue N, Miyamoto E: Calcineurin in human brain and its relation to extrapyramidal system. Immunohistochemical study on postmortem human brains. Acta Neuropathol 1986, 72(2):150-156.

23. Agostinho P, Lopes JP, Velez Z, Oliveira CR: Overactivation of calcineurin induced by amyloid-beta and prion proteins. Neurochem Int 2008, 52(6):1226-1233. 
24. Cardenas ME, Muir RS, Breuder T, Heitman J: Targets of immunophilin-immunosuppressant complexes are distinct highly conserved regions of calcineurin A. EMBO J 1995, 14(12):2772-2783.

25. Klionsky DJ, Emr SD: Autophagy as a regulated pathway of cellular degradation. Science 2000, 290(5497):1717-1721.

26. Glick D, Barth S, Macleod KF: Autophagy: cellular and molecular mechanisms. J Patho/ 2010, 221(1):3-12.

27. Komatsu M, Waguri S, Chiba T, Murata S, Iwata J, Tanida I, Ueno T, Koike M, Uchiyama Y, Kominami E et al: Loss of autophagy in the central nervous system causes neurodegeneration in mice. Nature 2006, 441(7095):880-884.

28. Hara T, Nakamura K, Matsui M, Yamamoto A, Nakahara Y, Suzuki-Migishima R, Yokoyama M, Mishima K, Saito I, Okano H et al: Suppression of basal autophagy in neural cells causes neurodegenerative disease in mice. Nature 2006, 441(7095):885-889.

29. Levine B, Kroemer G: Biological Functions of Autophagy Genes: A Disease Perspective. Cell 2019, 176(1-2):11-42.

30. Kyo R, Nakahata N, Sakakibara I, Kubo M, Ohizumi Y: Baicalin and baicalein, constituents of an important medicinal plant, inhibit intracellular $\mathrm{Ca} 2+$ elevation by reducing phospholipase $\mathrm{C}$ activity in C6 rat glioma cells. J Pharm Pharmacol 1998, 50(10):1179-1182.

31. Zhu JT, Choi RC, Chu GK, Cheung AW, Gao QT, Li J, Jiang ZY, Dong TT, Tsim KW: Flavonoids possess neuroprotective effects on cultured pheochromocytoma PC12 cells: a comparison of different flavonoids in activating estrogenic effect and in preventing beta-amyloid-induced cell death. J Agric Food Chem 2007, 55(6):2438-2445.

32. Choi RC, Zhu JT, Yung AW, Lee PS, Xu SL, Guo AJ, Zhu KY, Dong TT, Tsim KW: Synergistic Action of Flavonoids, Baicalein, and Daidzein in Estrogenic and Neuroprotective Effects: A Development of Potential Health Products and Therapeutic Drugs against Alzheimer's Disease. Evid Based Complement Alternat Med 2013, 2013:635694.

33. Moon JH, Park SY: Baicalein prevents human prion protein-induced neuronal cell death by regulating JNK activation. Int $J$ Mol Med 2015, 35(2):439-445.

34. Eiden M, Leidel F, Strohmeier B, Fast C, Groschup MH: A Medicinal Herb Scutellaria lateriflora Inhibits PrP Replication in vitro and Delays the Onset of Prion Disease in Mice. Front Psychiatry 2012, 3:9.

35. Wang YF, Xu YL, Tang ZH, Li T, Zhang LL, Chen X, Lu JH, Leung CH, Ma DL, Qiang WA et al: Baicalein Induces Beclin 1- and Extracellular Signal-Regulated Kinase-Dependent Autophagy in Ovarian Cancer Cells. Am J Chin Med 2017, 45(1):123-136.

36. Liu A, Huang L, Guo E, Li R, Yang J, Li A, Yang Y, Liu S, Hu J, Jiang X et al: Baicalein pretreatment reduces liver ischemia/reperfusion injury via induction of autophagy in rats. Sci Rep 2016, 6:25042.

37. Hung KC, Huang HJ, Wang YT, Lin AM: Baicalein attenuates alpha-synuclein aggregation, inflammasome activation and autophagy in the MPP(+)-treated nigrostriatal dopaminergic system in vivo. J Ethnopharmacol 2016, 194:522-529. 
38. Boland B, Kumar A, Lee S, Platt FM, Wegiel J, Yu WH, Nixon RA: Autophagy induction and autophagosome clearance in neurons: relationship to autophagic pathology in Alzheimer's disease. $J$ Neurosci 2008, 28(27):6926-6937.

39. Lonskaya I, Shekoyan AR, Hebron ML, Desforges N, Algarzae NK, Moussa CE: Diminished parkin solubility and co-localization with intraneuronal amyloid-beta are associated with autophagic defects in Alzheimer's disease. J Alzheimers Dis 2013, 33(1):231-247.

40. Kegel KB, Kim M, Sapp E, McIntyre C, Castano JG, Aronin N, DiFiglia M: Huntingtin expression stimulates endosomal-lysosomal activity, endosome tubulation, and autophagy. J Neurosci 2000, 20(19):7268-7278.

41. Nixon RA, Wegiel J, Kumar A, Yu WH, Peterhoff C, Cataldo A, Cuervo AM: Extensive involvement of autophagy in Alzheimer disease: an immuno-electron microscopy study. J Neuropathol Exp Neurol 2005, 64(2):113-122.

42. Forloni G, Angeretti N, Chiesa R, Monzani E, Salmona M, Bugiani O, Tagliavini F: Neurotoxicity of a prion protein fragment. Nature 1993, 362(6420):543.

43. Gu Y, Fujioka H, Mishra RS, Li R, Singh N: Prion peptide 106-126 modulates the aggregation of cellular prion protein and induces the synthesis of potentially neurotoxic transmembrane PrP. J Biol Chem 2002, 277(3):2275-2286.

44. Forloni G, Chiesa R, Bugiani O, Salmona M, Tagliavini F: Review: PrP 106-126 - 25 years after. Neuropathol Appl Neurobiol 2019, 45(5):430-440.

45. Corsaro A, Thellung S, Villa V, Principe DR, Paludi D, Arena S, Millo E, Schettini D, Damonte G, Aceto A et al: Prion protein fragment 106-126 induces a p38 MAP kinase-dependent apoptosis in SH-SY5Y neuroblastoma cells independently from the amyloid fibril formation. Ann N Y Acad Sci 2003, 1010:610-622.

46. Moon JH, Jeong JK, Hong JM, Seol JW, Park SY: Inhibition of Autophagy by Captopril Attenuates Prion Peptide-Mediated Neuronal Apoptosis via AMPK Activation. Mol Neurobiol 2019, 56(6):41924202.

47. Tsien RY, Pozzan T, Rink TJ: T-cell mitogens cause early changes in cytoplasmic free Ca2+ and membrane potential in lymphocytes. Nature 1982, 295(5844):68-71.

48. Hong JM, Moon JH, Park SY: Human prion protein-mediated calcineurin activation induces neuron cell death via AMPK and autophagy pathway. Int J Biochem Cell Biol 2020, 119:105680.

49. Moon JH, Park SY: Prion peptide-mediated calcium level alteration governs neuronal cell damage through AMPK-autophagy flux. Cell Commun Signal 2020, 18(1):109.

\section{Figures}




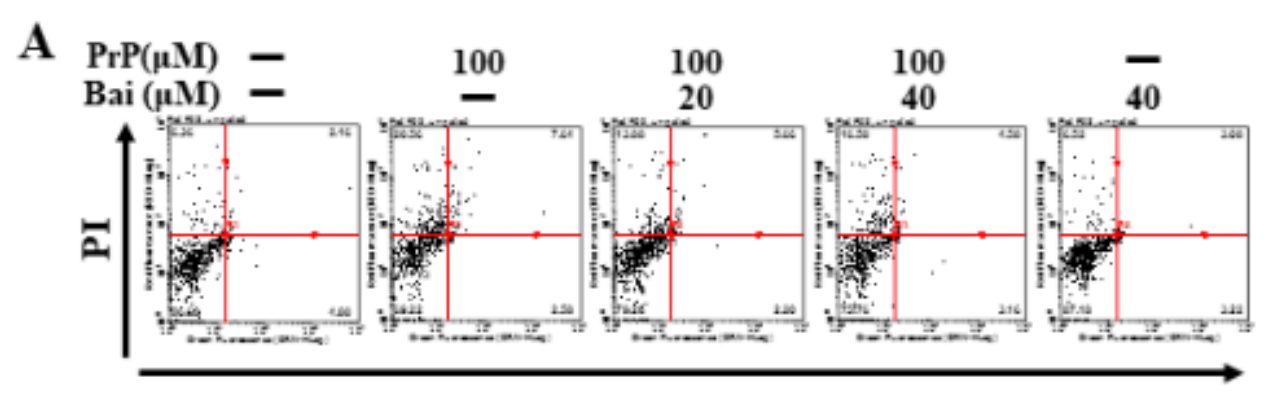

Annexin V - FITC
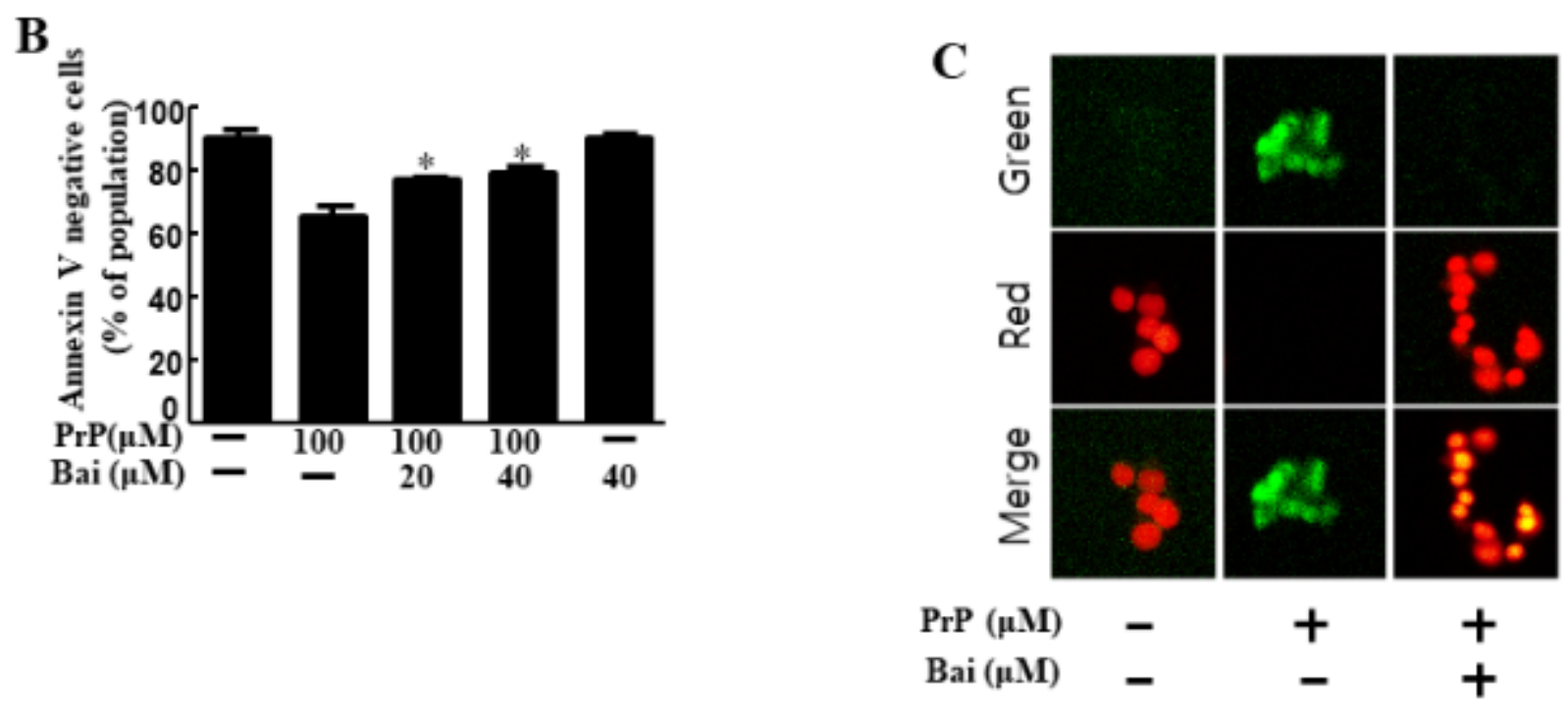

Fig.1 Hong et al.

\section{Figure 1}

Baicalein attenuates PrP (106-126)-induced cytotoxicity in neuronal cells. (A) SK-N-SH cells were treated with baicalein for $1 \mathrm{~h}$ and then exposed to $100 \mu \mathrm{M}$ of $\operatorname{PrP}(106-126)$ for $12 \mathrm{~h}$. Cell viability was measured by annexin V assay. Cells were treated with FITC-annexin V and PI, which bind to phosphatidylserine in the plasma membrane and nuclei during apoptosis. (B) Bar graph indicating the average number of annexin V-negative cells. (C) Representative immunofluorescence images of TUNEL-positive (green) SK$\mathrm{N}$-SH cells $12 \mathrm{~h}$ after exposure to $100 \mu \mathrm{M} \operatorname{PrP}(106126)$ in the absence or presence of baicalein $(1 \mathrm{~h})$. The cells were counterstained with PI (red) to show all cell nuclei. The bar graph shows the mean \pm standard error of the mean $(n=3) .{ }^{*} p<0.001$, significant differences when comparing the control group with each treatment group. PrP, Prion peptide (106-126) 

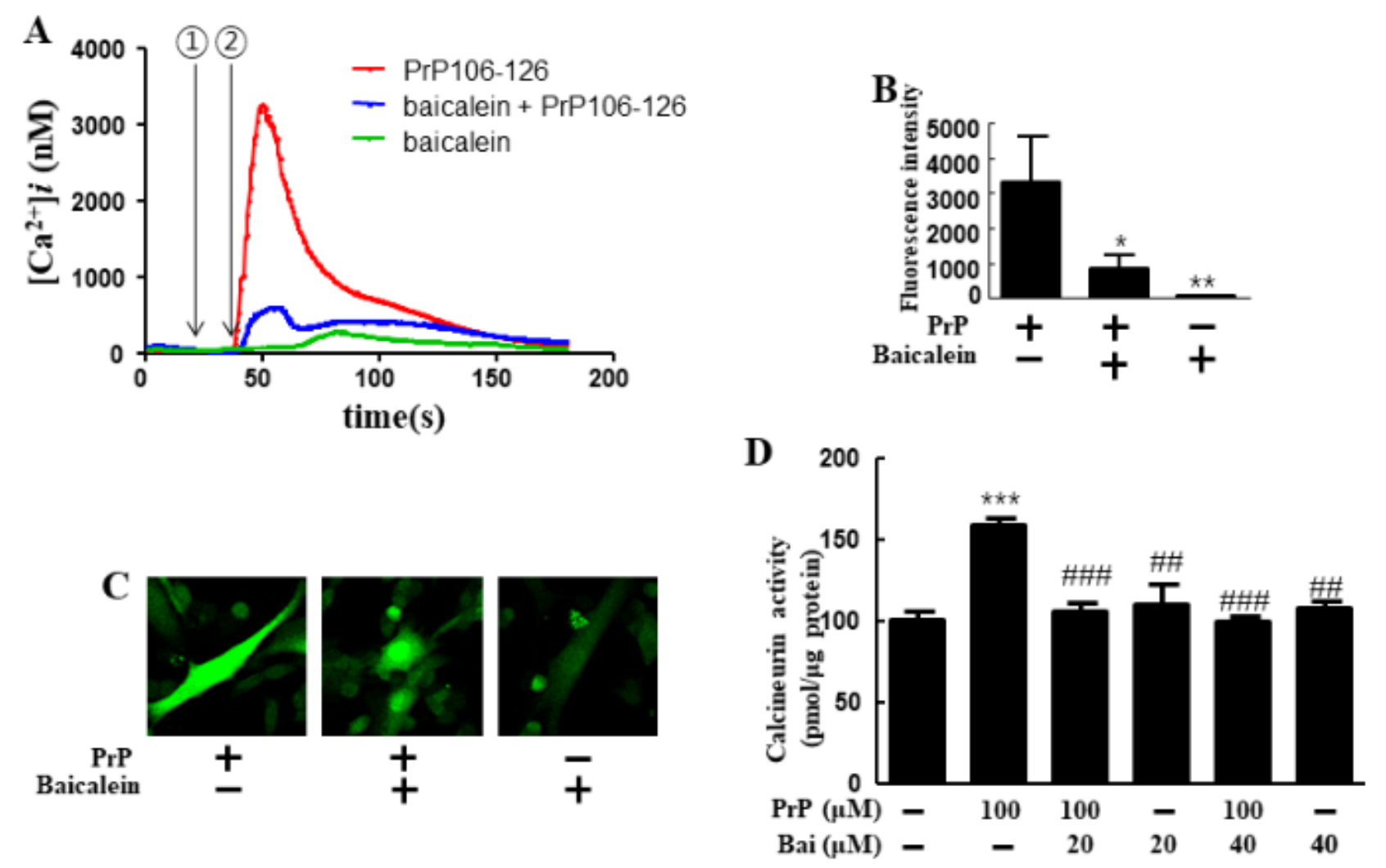

Fig.2 Hong et al.

\section{Figure 2}

Baicalein treatment inhibits PrP (106-126)-induced calcineurin. (A) SK-N-SH cells were loaded with fluo-4 $\mathrm{AM}$ and the changes in $\mathrm{Ca} 2+$ levels were measured using confocal microscope. The time point of $40 \mu \mathrm{M}$ of baicalein addition is indicated by the $\otimes$ arrow and $100 \mu \mathrm{M}$ of $\operatorname{PrP}(106-126)$ addition is indicated by the $\triangle$ arrow. Data are mean \pm SEM of [Ca2+]i at 60 s from three independent experiments. (B) Bar graph indicating the average peak value of intracellular calcium levels. (C) The green fluorescence image indicates peak value of calcium measurement using confocal microscopy. (D) SK-N-SH cells were treated with baicalein for $1 \mathrm{~h}$ and then exposed to $100 \mu \mathrm{M}$ of $\operatorname{PrP}(106-126)$ for $12 \mathrm{~h}$. The treated cells were assessed for calcineurin activity. The bar graph shows the mean \pm standard error of the mean from three independent experiments. ${ }^{* \star} p<0.001, \# p<0.05$; significant differences when compared with the control group and each treatment group. PrP, Prion peptide (106-126) 


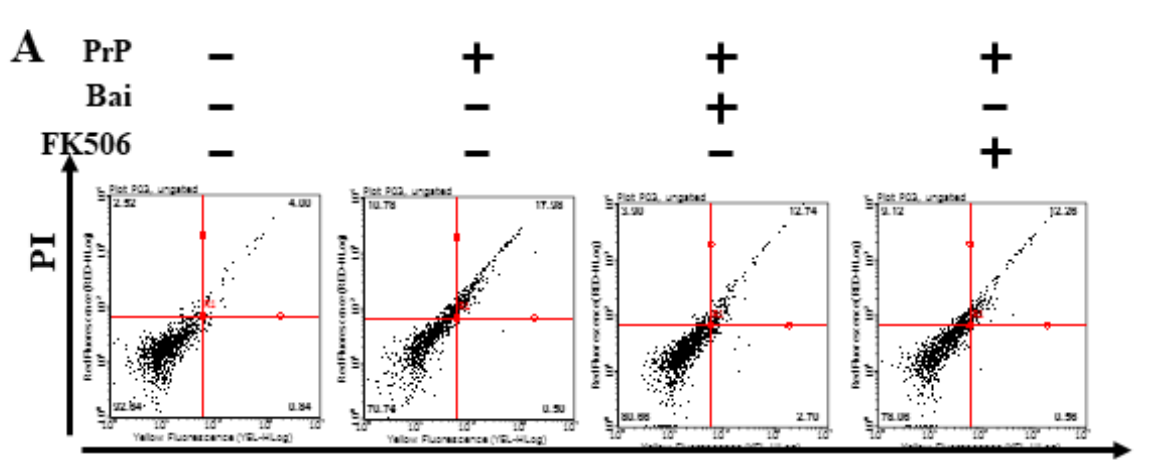

Annexin V - FITC
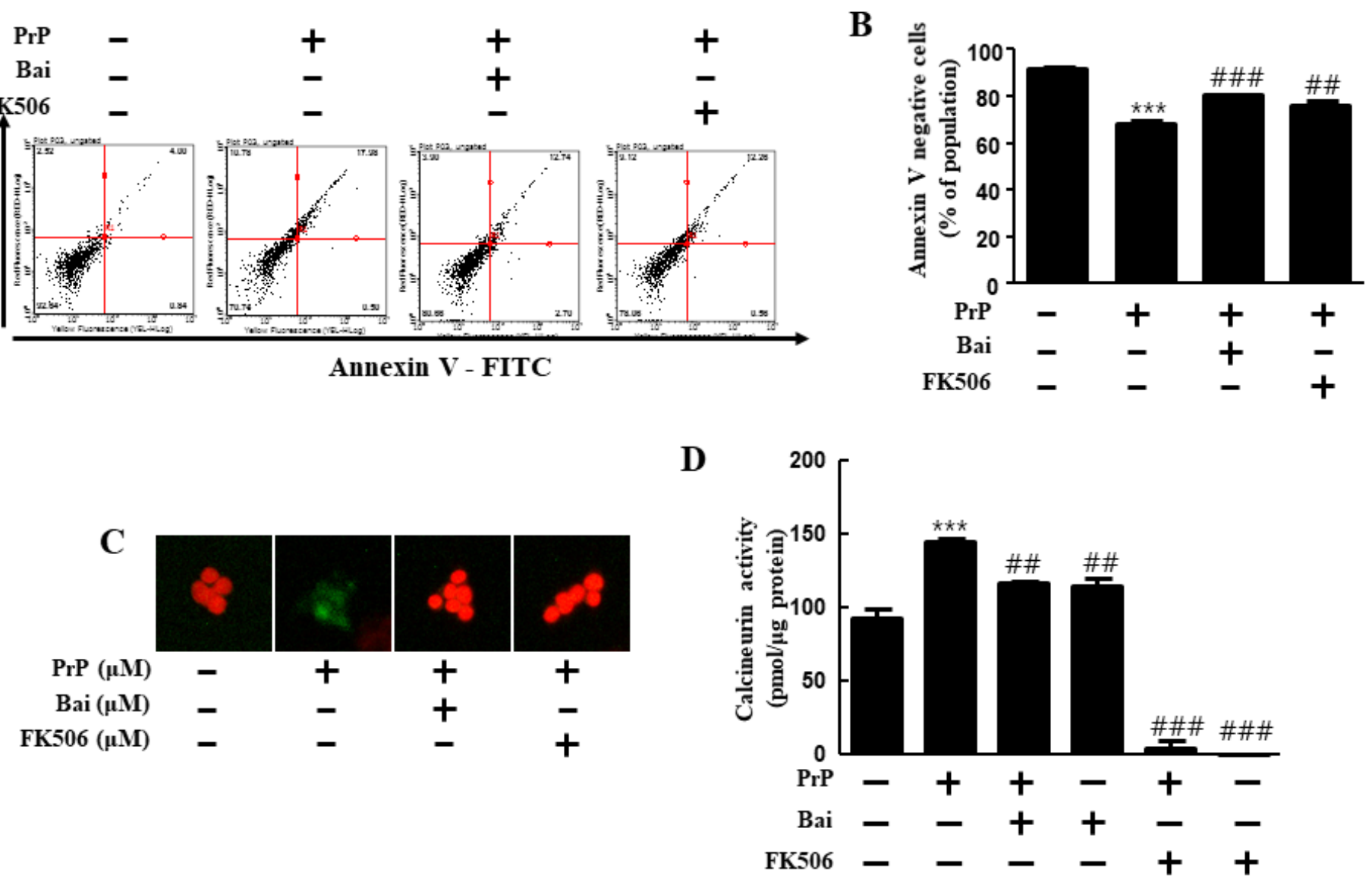

Fig.3 Hong et al.

\section{Figure 3}

Baicalein inhibits $\operatorname{PrP}$ (106-126)-induced neurotoxicity via calcineurin inhibition. (A) SK-N-SH cells were treated with baicalein and calcineurin inhibitor for $1 \mathrm{~h}$ and then exposed to $100 \mu \mathrm{M}$ of PrP (106-126) for $12 \mathrm{~h}$. Cell viability was measured by annexin V assay. Cells were treated with FITC-annexin V and PI, which binds to phosphatidylserine in the plasma membrane and nuclei during apoptosis. (B) Bar graph indicating the average number of annexin V-negative cells. (C) Representative immunofluorescence images of TUNEL-positive (green) SK-N-SH cells $12 \mathrm{~h}$ following exposure to $100 \mu \mathrm{M} \operatorname{PrP}(106 \mathrm{126})$ in the absence or presence of baicalein and calcineurin inhibitor (FK506) $(1 \mathrm{~h})$. The cells were counterstained with PI (red) to visualize all cell nuclei. (D) SK-N-SH cells were treated with baicalein and calcineurin inhibitor for $1 \mathrm{~h}$ and then exposed to $100 \mu \mathrm{M}$ of $\operatorname{PrP}(106-126)$ for $12 \mathrm{~h}$. The treated cells were assessed for calcineurin activity. The bar graph shows the mean \pm standard error of the mean $(n=3) . \star \star \star p<0.001$, $\# \# p<0.01$, \#\#\# $p<0.001$; significant differences when comparing the control group with each treatment group. PrP, Prion peptide (106-126) 

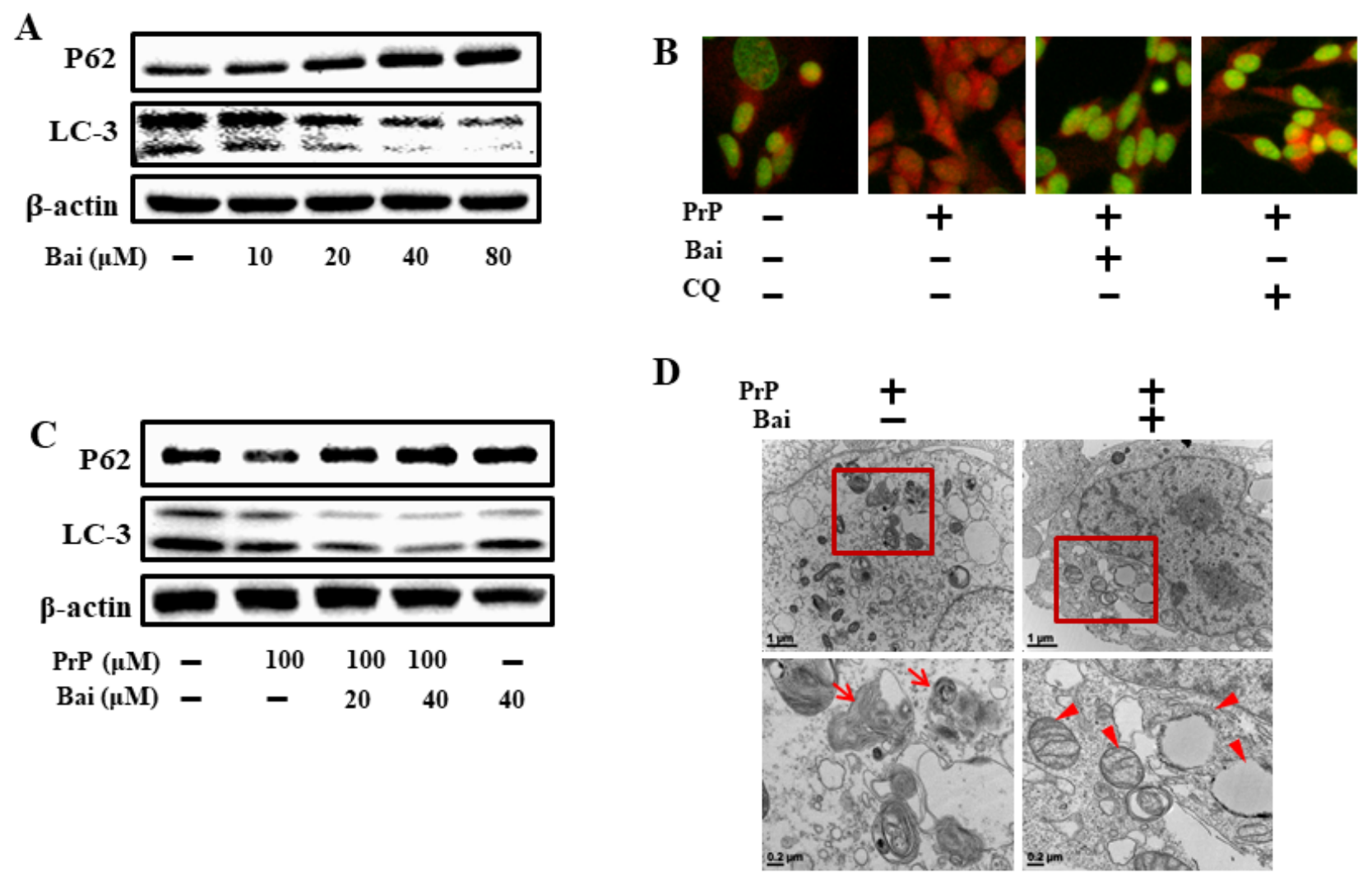

Fig.4 Hong et al.

Figure 4

Baicalein inhibited autophagy. (A) SK-N-SH cells were treated with $10,20,40$ and $80 \mu \mathrm{M}$ of baicalein for $12 \mathrm{~h}$. The treated cells were assessed for P62, LC3 by Western blot analysis. (B) Orange fluorescence was recovered with baicalein and autophagy inhibitor. (C) SK-N-SH cells were treated with baicalein for $1 \mathrm{~h}$ and then exposed to $100 \mu \mathrm{M}$ of PrP (106-126) for $12 \mathrm{~h}$. The treated cells were assessed for P62, LC3 by Western blot analysis. (D) SK-N-SH cells were treated with baicalein for $1 \mathrm{~h}$ and then exposed to $100 \mu \mathrm{M}$ of PrP (106-126) for $12 \mathrm{~h}$ and analyzed by TEM. Arrows indicate autophagosomes and arrowheads indicate lysosomes and mitochondria. 


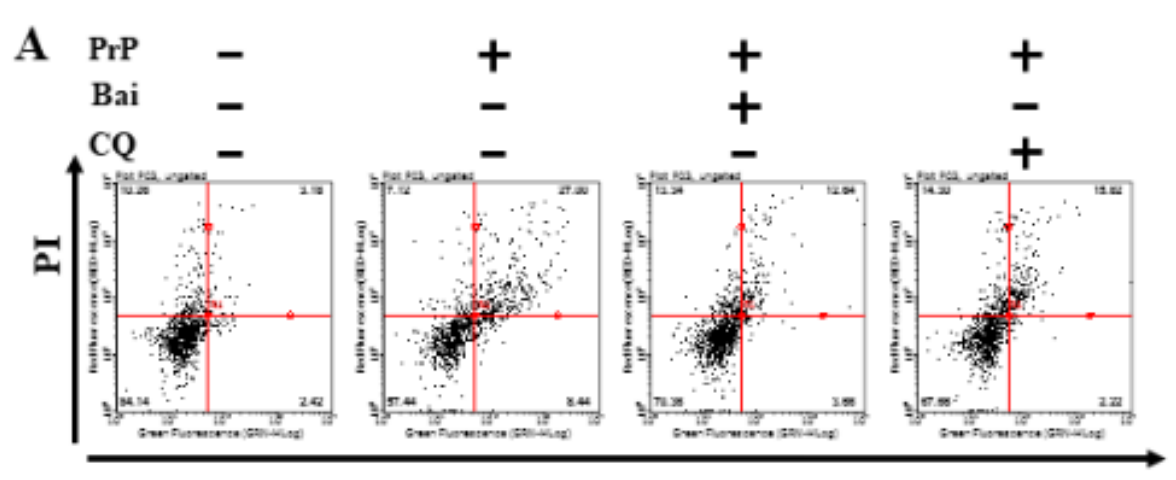

Annexin V - FITC
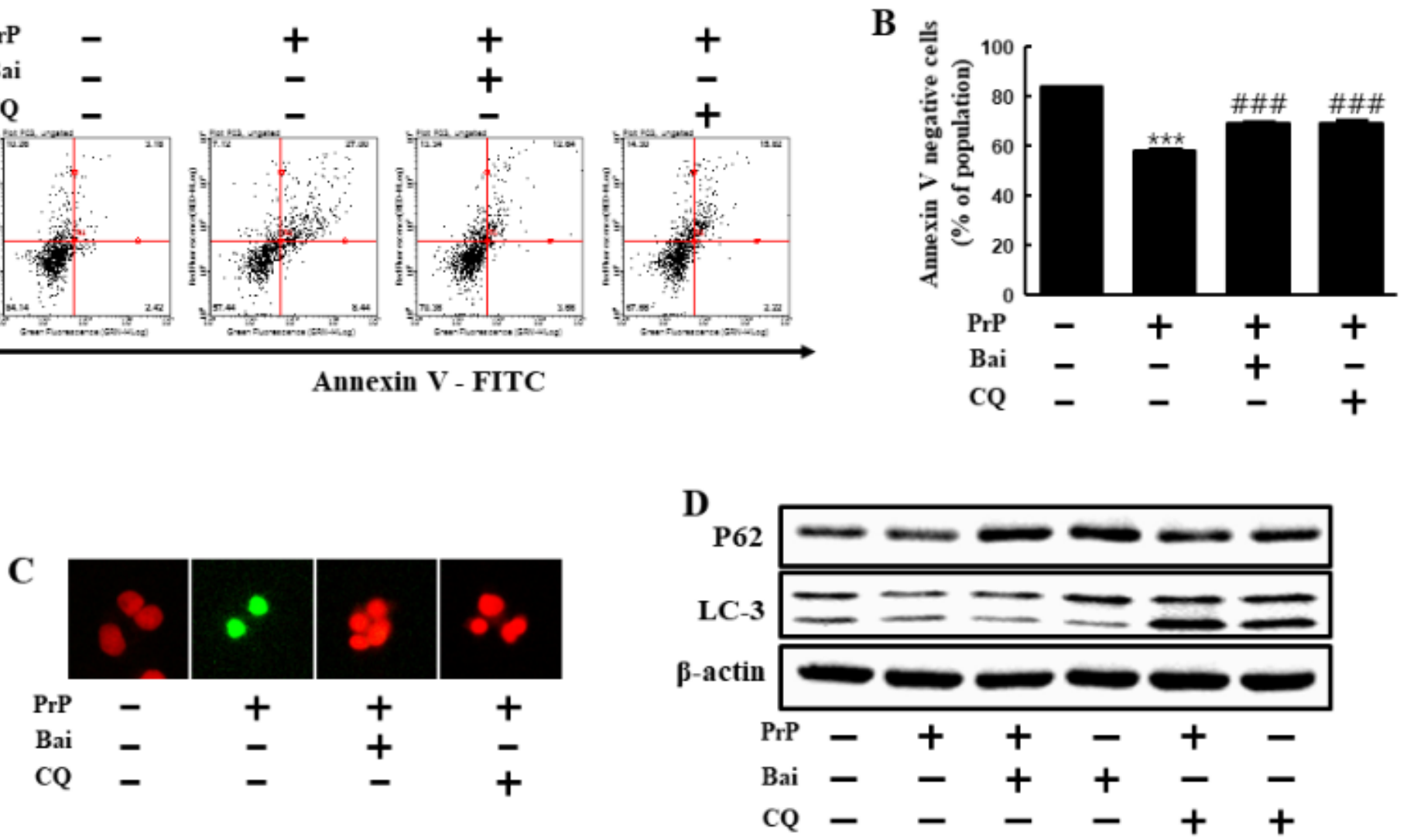

Fig.5 Hong et al.

\section{Figure 5}

Baicalein inhibited PrP(106-126)-induced neurotoxicity via autophagic flux. (A) SK-N-SH cells were treated with baicalein and autophagy inhibitor for $1 \mathrm{~h}$ and then exposed to $100 \mu \mathrm{M}$ of $\operatorname{PrP}(106-126)$ for $12 \mathrm{~h}$. Cell viability was measured by annexin V assay. Cells were treated with FITC-annexin V and PI, which binds to phosphatidylserine in the plasma membrane and nuclei during apoptosis. (B) Bar graph indicating the average number of annexin V-negative cells. (C) Representative immunofluorescence images of TUNELpositive (green) SK-N-SH cells $12 \mathrm{~h}$ following exposure to $100 \mu \mathrm{M} \operatorname{PrP}(106126)$ in the absence or presence of baicalein and autophagy inhibitor $(1 \mathrm{~h})$. The cells were counterstained with $\mathrm{PI}(\mathrm{red})$ to show all cell nuclei. (D) SK-N-SH cells were treated with baicalein and autophagy inhibitor for $1 \mathrm{~h}$ and then exposed to $100 \mu \mathrm{M}$ of PrP (106-126) for 12h. The treated cells were assessed for P62 and LC3 by Western blot analysis.

\section{Supplementary Files}

This is a list of supplementary files associated with this preprint. Click to download. 
- FigS4.TIF

Page 17/17 